\title{
La naturaleza de la biología en la formación inicial del profesorado: la intervención experimental y su importancia en la construcción del conocimiento científico
}

The nature of biology in pre-service teacher education: experimental intervention and its importance for the construction of scientific knowledge

Lorena Inzillo, Enrique M. Rodríguez y Agustín Adúriz-Bravo

Facultad de Ciencias Exactas y Naturales (FCEyN), Universidad de Buenos Aires (UBA), Giudad Autónoma de Buenos Aires, Argentina E-mail (primera autora): loreinzillo@gmail.com

\section{Resumen}

La presente investigación busca examinar las aportaciones de la llamada naturaleza de la biología a la formación inicial del profesorado para la educación secundaria. Las visiones actuales sobre la enseñanza de las ciencias proponen que esta no debería involucrar únicamente el aprendizaje de los resultados establecidos de la ciencia; en lugar de eso, debería también enfocarse en los procesos y metodologías usados por los científicos y científicas para alcanzar tales resultados. Por eso se desea indagar particularmente sobre cómo lo que se conoce como "intervención experimental" en la investigación cient́fica puede ser una idea epistemológica importante para equipar a los profesores y profesoras con imágenes más robustas de ciencia y de científico, que les permitan diseñar una biología escolar más significativa. La intención es, entonces, acercar al profesorado a los conceptos dave de la mirada metodológica sobre la ciencia.

\section{Palabras clave}

Ciencia escolar, naturaleza de la biología, formación del profesorado, imágenes de ciencia y de científico, intervención experimental.

\section{Abstract}

The present research seeks to examine the contributions of the so-called nature of biology to the pre-service education of biology teachers for secondary schools. Current views on science teaching propose that this should not only involve the leaming of established scientific results; instead, science teaching should also focus on the processes and methodologies used by scientists to reach those results. This is why the particularly aim of this study is exploring how what is known as 'experimental intervention' in scientific research can be a key epistemological idea to provide teachers with more robust images of science and of scientists, which would enable them to design a more meaningful school biology. The intention is, then, to acquaint teachers with some key concepts of the methodological perspective on science.

\section{Keywords}

School science, nature of biology, teacher education, images of science and of scientists, experimental intervention.

\section{Introducción}

En la actualidad el mundo se encuentra sujeto a trasformaciones muy profundas con implicaciones en diversos ámbitos; entonces, la educación en las ciencias naturales y sus 
respectivas tecnologías resulta de una importancia aucial para formar personas críticas, participativas, solidarias y tolerantes. Una finalidad central de la educación de calidad para todos y todas es la alfabetización cientŕfico-tecnológica de la población (Acevedo et al., 2005); en este contexto, la actual didáctica de las ciencias naturales (entendida como disciplina tecnocientífica autónoma y consolidada) se erige como un campo de referencia indispensable a la hora de mejorar la enseñanza de la biología en los distintos niveles educativos.

Dentro de la didáctica, la línea de reflexión metateórica acerca de las propias ciencias naturales conocida como "naturaleza de la ciencia" (NOS, por sus siglas en inglés) es un importante insumo que se viene produciendo en los últimos años para conseguir una enseñanza de las ciencias que supere la transmisión de contenidos terminados (la "retórica de condusiones") y se pregunte por cómo hemos llegado a saber eso que sabemos. Actualmente existe consenso acerca de que la educación cient́fica debería involucrar, además de saber ciencias, saber sobre ciencias; centrándose en esta idea es que avanzan las investigaciones sobre las distintas aportaciones que las metaciencias (epistemología, historia de la ciencia, sociología de la ciencia) pueden hacer a la reflexión teórica sobre la educación cientúfica (Acevedo et al., 2005; Adúriz-Bravo, 2005).

La inclusión de contenidos metacientíicos en los aurículos de biología (qué es y cómo se elabora la biología, cómo cambia en el tiempo, cómo se relaciona con la sociedad y la cultura) intenta generar en los y las estudiantes unas imágenes de ciencia y de cientúfico más ajustadas a las ideas actuales sobre el conocimiento y la actividad cientúficas (Adúriz-Bravo, 2005). Las nuevas metas prodamadas para el curnículo de biología escolar requieren de la adecuación de programas, metodologías y materiales y, fundamentalmente, de la producción de ideas y propuestas para la formación inicial y continuada del profesorado de biología, a fin de prepararlo para la enseñanza de estos "nuevos" contenidos de naturaleza de la ciencia, poco presentes en la formación docente tradicional.

Ahora bien, la introducción de la naturaleza de la biología en la formación del profesorado hace necesaria la discusión acerca de qué perspectivas metateóricas enseñarles. El presente proyecto se centra en recoger algunas "pistas" que la naturaleza experimental de la biología puede damos para una enseñanza de mejor calidad. Para ello se trabaja con la idea teórica de intervención (Hacking, 1983), entendiéndola como un modelo irreducible de la naturaleza de la biología. En este sentido, la intención es tratar de acercar a los profesores y profesoras de biología, particularmente durante su formación inicial, a algunos conceptos e ideas dave de la mirada metodológica actual sobre la ciencia, sobre todo, a aquellos vinculados a la experimentación en el laboratorio.

Si bien la experimentación no puede tener el mismo lugar en las aulas escolares que en la ciencia de los cient́ficos, ni el mismo valor epistemológico, los cient́ficos y cient́ficas consideran que la construcción del conocimiento teórico es fuertemente experimental; se ve a la experimentación como una de los recursos retóricos más importantes de la ciencia, un poderoso motor de producción de evidencias. Sin embargo, muy pocos y pocas estudiantes sacan ventaja de la experimentación escolar para la construcción "dialógica" de conocimiento teórico. Sería importante entonces resolver esta contradicción, diseñando una actividad científica escolar epistemológicamente fundamentada (Izquierdo-Aymerich y Adúriz-Bravo, 2003) que permita a los y las estudiantes apropiarse de la experimentación como parte esencial de la actividad cientúfica. La reconstrucción "semiótica" de la experimentación a partir de la escritura y la comunicación de las experiencias es un puntal importante para el logro de este objetivo, y además involucra a los y las estudiantes en el aprendizaje de cómo escribir y hablar ciencias. Este punto es también un punto central a la hora de promover una apreciación más robusta de la naturaleza de la ciencia.

Esta propuesta de formación del profesorado de biología está fundamentada teóricamente en el modelo cognitivo de ciencia escolar (Izquierdo-Aymerich y Adúriz-Bravo, 2003), que caracteriza la ciencia en el aula como una actividad cognitiva y discursiva, además de meramente material. El 
marco teórico que se utiliza acuerda con una concepción semántica de las teorías científicas y una visión basada en modelos, y está inspirado en la filosofía cognitiva de la ciencia del epistemólogo estadounidense Ronald Giere (1988). Se trata de proveer una visión continuista o unificadora de la ciencia escolar y la ciencia enudita, viendo la natural progresión entre una y otra actividad, ambas caracterizadas por su objetivo cognitivo de "dar sentido" (Izquierdo-Aymerich, 2005).

\section{Desarrollo}

En este trabajo se intenta caracterizar las imágenes de ciencia y de científico que poseen los profesores y profesoras de biología para el nivel secundario en formación y en ejercicio. Se quiere indagar las posibles contribuciones de lo que llamamos la naturaleza de la biología al robustecimiento de esas imágenes y, en definitiva, a la tarea profesional de enseñar biología.

En particular se pretende revisar cómo la idea de intervención de carácter experimental en la investigación biológica puede aportar "pistas" para dotar al profesorado de biología de una mirada más epistemológicamente acabada de la biología, mirada que les permita diseñar una actividad científica escolar más rica y más coherente con los actuales objetivos curriculares validados socialmente.

La intención es entonces acercar a los profesores y profesoras de biología, sobre todo quienes transitan su formación inicial en el ámbito de la universidad, a los conceptos e ideas dave de la mirada metateórica de carácter metodológico sobre la ciencia, tratando de que ese utillaje teórico se traduzca en una biología escolar más significativa para los y las estudiantes.

Ahora bien, teniendo en mente el propósito de "detectar" aquellas ideas daves de la epistemología reciente y actual que han sido diseñadas para pensar la experimentación científica y que, al mismo tiempo, resultan un aporte relevante y funcional para la actividad del profesorado de biología, aparecen una serie de preguntas de investigación. ¿De qué manera la intervención experimental modifica los modos de pensar, decir y hacer de los científicos y cientúficas? ¿Qué aspectos de esa intervención se pueden trasmitir en la enseñanza de las ciencias? ¿Cómo puede diseñarse una actividad cientúfica escolar que haga pie en esos aspectos sin distorsionarlos? ¿Cómo se puede formar a los profesores y profesoras de biología con imágenes de ciencia y de científico "bien transpuestas" en tomo a la cuestión del experimento? ¿Cómo acompañar al profesorado en su tránsito de profesionalización para que sean capaces de diseñar actividades significativas para la apropiación de la noción de que la intervención experimental es una parte fundamental de la actividad cientúfica, pero no se reduce a la materia prima de la cual se "generaliza" la teoría?

Como objetivos espeáficos de este trabajo, se propone el análisis crítico y la expansión de la fundamentación teónica disponible acerca de la importancia de enseñar la naturaleza de la biología a los profesores. Además se desea llevar adelante aplicaciones prácticas del corpus de conocimiento disponible en tormo a esta cuestión, desarrollando materiales, estrategias y herramientas para la educación en la naturaleza de la biología, haciendo foco en la noción de intervención experimental. Por último, se pretende evaluar críticamente la puesta en práctica de lo que se vaya diseñando, a fin de analizar su aporte a la mejora del pensamiento cítico y de la práctica profesional de los profesores y profesoras de biología. Los profesores y profesoras de ciencias suelen tener concepciones y conocimientos prácticos muy estables, que fueron formados y consolidados a lo largo de su práctica (Mellado, 2003, en Vázquez 2006) por eso es importante que los contenidos de la naturaleza de la biología estén en la formación inicial del profesorado.

Para llevar a cabo los propósitos del proyecto, se están analizando los marcos teóricos existentes y también se está comenzando a desarrollar categońas y constructos teóricos que posibiliten posteriormente el análisis y la producción de materiales, herramientas y actividades, 
tanto propias como ajenas, que hagan "emerger" una naturaleza de la biología apropiada para la tarea docente. Además se quiere desarrollar secuencias de enseñanza de la naturaleza de la biología eficaces para que el profesorado se apropie significativamente de este contenido y lo transfieran a su práctica de aula.

Teniendo en cuenta que muchas veces los aspectos metodológicos de la ciencia son trasmitidos a los científicos y cient́ficas noveles generalmente en el intercambio y la relación estrecha con sus pares más formados, es importante considerar la dificultad que representa, para el profesorado que no se ha formado como profesional de la ciencia, poder reconocer y trasmitir de maneras no distorsivas el valor constructivo de la experimentación. Por eso es sumamente importante realizar un análisis del rol epistemológico que juega la misma en el desarrollo de la ciencia, y desentrañar sus características más salientes, a fin de poder diseñar secuencias didácticas que permitan a los profesores y profesoras de biología en formación apropiarse realmente de la experimentación en todas sus dimensiones. Ello les permitiría ser capaces de construir, a ellos mismos, conocimiento cientúfico escolar y también hacer intervenciones experimentales más "genuinas" en el aula.

En la actualidad la intervención experimental en biología es muy variada, estando las metodologías específicas en cada caso íntimamente relacionadas con el recorte del mundo biológico sobre el que se ha decidido intervenir, ya sea para conocerlo como para modificarlo. Esto que a veces parece tan obvio no es un detalle menor, ya que se relaciona con la imposibilidad de enseñar un único "método cient́fico" sancionado en el cual la experimentación ocupa un pedestal de primaća empiropositivista. La naturaleza profunda de la metodología experimental está ligada al objeto de estudio, y de alguna manera sobredeterminada por él; sin embargo, la biología (como todas las demás ciencias) posee una diversidad de propósitos, finalidades y valores que hacen que cada acercamiento al objeto requiera de matices propios.

De aquí se sigue la necesidad de que la enseñanza de la biología tenga en cuenta variadas formas de construir conocimiento. Los procesos para la creación de "modos de ver el mundo" y de "reglas del juego" son muy variados; sería insostenible pretender que los y las estudiantes los reduzcan a un encorsetado "método científico". Parece fundamental que el profesorado de biología ponga en juego en clase la idea de que la experimentación es una forma, culturalmente conquistada, de interrogar al mundo. Para tal fin resulta necesario proponer intervenciones formativas que pongan sobre el tapete preguntas tales como: ccómo puedo conocer determinado objeto biológico?, ¿qué tipo de preguntas me debo hacer?, ¿auáles son las reglas de juego para intervenir sobre él?, ¿qué tipo de "acciones" experimentales son pertinentes?

Desde el punto de vista metodológico, y en coherencia con los propósitos, preguntas y objetivos expuestos más arriba, en este trabajo se van a utilizar fundamentalmente tres "herramientas": 1. la historia de la ciencia, reconociendo episodios significativos y paradigmáticos de la biología que pueden fomentar la reflexión acerca de su naturaleza; 2 las analogías (diseñadas especialmente para la enseñanza), que permiten la apropiación de metamodelos a partir de aproximaciones más cercanas a la vida cotidiana; y 3. el lenguaje científico, como forma de acercamiento al proceso de comunicación de y sobre la ciencia en la cual se ponen en juego distintas habilidades cognitivolingüísticas de alto vuelo, como la argumentación, la explicación, la analogación o la abducción.

\section{Conclusiones}

Se puede afimar que la naturaleza experimental de la ciencia se revela daramente como un conocimiento dave y estructurador que debe enseñarse. Ya que la generación experimental de evidencias y la transformación activa del mundo real mediante la experimentación controlada son parte fundamental de la actividad cientíica, no pueden quedar afuera del currículo de biología para todos y todas si se busca lograr imágenes de ciencia y de científico más acordes con lo que 
actualmente se sabe desde la epistemología y las demás metaciencias. Si bien el proyecto se encuentra en instancias preliminares y no se tienen aún condusiones formalizadas acerca de cuáles son las aportaciones más centrales y significativas de la naturaleza de la biología para la formación del profesorado en tomo a la cuestión de la intervención experimental.

Además, las diversas formas de experimentación, el uso de la tecnología, y los protocolos cada vez más sofisticados y complejos no sólo permiten poner a prueba las hipótesis de los cientúficos y cientúficas, sino que transforman sus procesos cognitivos y discursivos, es decir que la experimentación cambia la forma de pensar y decir de las personas. Considerando esto, si se desea lograr que circulen socialmente imágenes más robustas y educativas de qué es y cómo se produce el conocimiento científico, es esencial involucrar a los y las estudiantes en el trabajo experimental y en la idea de que la actividad científica interviene transformadoramente en el mundo (Hodson, 1994; Izquierdo-Aymerich, 2005).

Sin embargo, hay investigaciones que muestran que el involucrar a los y las estudiantes en procesos de investigación guiada o autónoma, si bien puede acercarlos a la actividad científica, no necesariamente habilita el aprendizaje de conocimiento metateórico sobre la ciencia (cf. Hodson, 1994). Es decir, el "hacer ciencia" en la escuela no conduce directamente a entender su naturaleza; por ello es importante destinar tiempo a la enseñanza explícita de estos nuevos contenidos. Además, como se mencionó previamente las concepciones de profesores y profesoras son difíciles de modificar, sin embargo si se implican en un proceso reflexivo, la reflexión y la intervención en el aula se retroalimentan constantemente (Vázquez, 2006). Por todo lo expuesto para este trabajo es necesario entonces diseñar auidadosamente una reflexión intencionada acerca de qué es la experimentación cient́fica (erudita y escolar), cuál es su valor epistemológico, cómo se comunica esa experimentación al interior y al exterior de la comunidad (escolar y científica), y cuál es su utilidad para la construcción de conocimiento.

\section{Bibliografía}

Acevedo, J.A., Vázquez, Á., Martín, M, Oliva, J.M., Acevedo, P., Paixão, M.F. y Manassero, M.A. (2005). Naturaleza de la ciencia y educación cient́fica para la participación ciudadana: Una revisión cítica. Revista Eureka sobre Enseñanza y Divulgación de las Ciencias, 2(2), 121-140.

Adúriz-Bravo, A. (2005). Una introducción a la naturaleza de la ciencia: La epistemología en la enseñanza de las ciencias naturales. Buenos Aires: Fondo de Cultura Económica.

Giere, R. (1988). Explaining science: A cognitive approach. Chicago: Chicago University Press.

Hacking, I. (1983). Representing and intervening. Cambridge: Cambridge University Press.

Hodson, D. (1994). Hacia un enfoque más crítico del trabajo de laboratorio. Enseñanza de las Ciencias, 12, 299-313.

Izquierdo-Aymerich, M. (2005). Hacia una teoría de los contenidos escolares. Enseñanza de las Ciencias, 23(1), 111-122

Izquierdo-Aymerich, M y Adúriz-Bravo, A. (2003). Epistemological foundations of school science. Science \& Education, 12(1), 27-43.

Vázquez Bemal, B., Jiménez Pérez, R, Mellado Jiménez, V. y Taboada Leñero, C. (2006) El análisis de la epistemología del conocimiento escolar. Revista Mexicana de Investigación Educativa, 11 (31), 1259-1286. 